\title{
Immunophenotype Study in Children with Leukemia and Its Relationship with Relapse in Ahvaz Shafa Hospital from 2013 to 2018
}

\author{
Arash Alghasi ${ }^{1} \&$ Jamshid Safdarian ${ }^{2}$ \\ ${ }^{1}$ Thalassemia \& Hemoglobinopathy Research center, Health research institute, Ahvaz Jundishapur University of \\ Medical Sciences, Ahvaz, Iran \\ ${ }_{2}^{2}$ Pediatric Resident, Ahvaz Jundishapur University of Medical Sciences, Ahvaz, Iran \\ Correspondence: Jamshid Safdarian, Pediatric Resident, Ahvaz Jundishapur University of Medical Sciences, \\ Ahvaz, Iran. E-mail: jamshidsafdarian@yahoo.com
}

Received: June 1, 2019

Accepted: June 13, 2019

Online Published: June 21, 2019

doi:10.5539/jmbr.v9n1p61

URL: https://doi.org/10.5539/jmbr.v9n1p61

\begin{abstract}
Introduction: Acute lymphoblastic leukemia (ALL) is one of the most common cancers in children. Since the identification of patients immunophenotypes is effective for disease diagnose and prognosis, and due to very few studies in Iran, especially Khuzestan province, the aim of this study was to investigate the immunophenotype of children with leukemia and its association with recurrence in Ahvaz Shafa Hospital from 2013 to 2019.

Methods: This is a retrospective study that was conducted in patients referring to Ahvaz Shafa Hospital during the years 2013 to 2019. Demographic data including age, gender, height, weight, leukocyte count, flow cytometry and other laboratory findings were collected and analyzed by version 22 SPSS statistical software.

Results: The mean age of the patients was $7.59 \pm 3.94$ years and the sex of $51(52 \%)$ were female. Immunophenotype of 81 patients $(82.7 \%)$ was Pre B cell, 4 patients (4.1\%) was Pro-B Cell, 5 patients (5.1\%) was Pro-T Cell, and 8 patients (8.2\%) was T Cells. 87 patients $(88.8 \%)$ recovered and 11 patients $(11.2 \%)$ had recurrence. Only 11 patients with Pre B cell (13.6\%) had recurrence, but in other immunophenotypes, $100 \%$ of patients had remission, but this difference was not statistically significant $(p=0.46)$. There was no statistically significant difference between the prevalence of phenotypes in female and male sexes $(p=0.76)$. The incidence of recurrence was $9.8 \%$ in female patients and $12.8 \%$ in male patients, which was not statistically significant ( $p$ $=0.64$ ).

Conclusion: The results of this study showed that preB cell immunophenotypes with the prevalence of $82.7 \%$ had the highest frequency in acute lymphoblastic leukemia, and the incidence of recurrence in patients was $11.2 \%$. Also, patients with other immunophenotypes did not recurrence, so his finding may have been because of insufficent patients to study and compare.
\end{abstract}

Keywords: Acute Lymphoblastic Leukemia, Immunophenotype, Pre B Cell ALL

\section{Introduction}

Cancer is the second leading cause of death in children between the ages of 1 to 14, and the most common type of this, is leukemia (Espirito, Gaiva, Espinosa, Barbosa, \& Belasco, 2011; Litzelman, Catrine, Gangnon, \& Witt, 2011). About $32 \%$ of childhood cancers are related to leukemia. The most common form of leukemia in children is acute lymphoblastic leukemia (ALL) (Karimi, Mehrabani, Yarmohammadi, \& Safari Jahromi, 2008). World reports, state that the prevalence of leukemia in the world for the period from 0 to 19 years is about 6.05 per 100,000 people (Barrington-Trimis, Cockburn, Metayer, Gauderman, Wiemels, \& McKean-Cowdin, 2016). Research has shown that leukemia is the most common cancer in children between 0 to 14 years old in Iran, and the incidence of it, estimated 8 to 62 cases per million (Mousav, Pourfeizi, \& Dastgiri, 2010). Risk factors are classified as peripheral, genetic, and infectious factors. The disease also presents a variety of morphological, cytogenetic and immunologic characteristics of the modified cells, which lead to various clinical signs and various responses to treatment in this disease (Chiaretti \& Foà, 2009; Hunger \& Mullighan, 2015). Clinical signs of this disease include colony proliferation, apoptosis and malignant proliferation of immature lymphoid cells that stop at various stages of cell proliferation within the bone marrow and lymphoid tissues (Aghamohammadi et al., 2008; Pui et al., 2015). The number of white blood cells in patients with acute lymphoblastic leukemia has increased and organomegaly, especially mediastinal enlargement, as well as involvement of the nervous system 
have been observed in this disease, which initial manifestations of ALL are usually mild and non-specific, and includes fever, fatigue, irritability, mild and alternate fever, bony or joint pain, especially in the lower extremity, and often there is a history of an upper respiratory tract infection in the last 1-2 months (Azimi, Aghamohammadi, Ramyar, Safari, Divsalar, \& Mahmoodi, 2012; Masoomeh \& Marjan, 2011).

In the environmental risk factors group, is ionizing radiation, which is significantly related to ALL and AML (Belson, Kingsley, \& Holmes, 2007; Mahoney et al., 2004; Nikpour, Rahimian, Shokrabi, \& Haghani, 2010). The history of abortion and the risk of leukemia have also been studied in several studies and controversial results have been achieved (Hassanzade, Mohammadi, \& Rajaeefard, 2013; Vazirianzadeh, Maraghi, Samie, Vazirianzadeh, Montazeri, \& Eghbalnejad Mofrad, 2017). specific hereditary diseases such as Falconi's anemia, Bloom syndrome, Ataxia-telangiectasia and Neurofibromatosis are associated with leukemia. It has also been reported that the incidence of this disease in boys is more than that of girls (Masoomeh \& Marjan, 2011). Also, several indirect factors encounter infectious agents such as birth rate, attendance at daycare centers and kindergartens, exposure to pets, and the likelihood of children with leukemia, have been correlated. But only $10 \%$ of the cases of childhood cancers are clinically and epidemiologically justifiable, and in $90 \%$ of cases, no specific etiology has been identified. Like other cancers, it appears that children's leukemia is a multifactorial illness, with environmental and genetic factors contradiction (Buffler, Kwan, Reynolds, \& Urayama, 2005).

ALL using immunological markers is divided into 4 major subtypes: early pre B cell, Pre B cell, B cell, and T cell, which the subtype of early pre B cell is the most common type among children (Entezar-e-Ghaem, Rahgozar, Moafi, Moshtaghian, Esmaeli, Abedi, \& Montazeri, 2013). Detection of lymphoproliferative disorders requires the use of several technologies, such as cellular histology, cytogenetics and the study of immunological cell markers. Flow cytometry provides a quick and accurate examination of the body's immune system, cancer cells, chromosomes, DNA levels, and levels of cell and cytoplasmic surface antigens (Vahedi, Ëstakhri, Goldoost, \& Goldoost, 2011). Since the identification of immunophenotypes of patients to diagnose the disease as well as its prognosis is effective, and due to very few studies in Iran, especially Khuzestan province, the aim of this study was to investigate the immunophenotype of children with leukemia and the association with recurrence Ahvaz Shafa Hospital from 2013 to 2019.

\section{Material and Method}

This study is a retrospective study that was conducted in patients referring to Ahvaz Shafa Hospital during the years 2013 to 2019. The pre-implementation study was approved by the University's Ethics Committee. arrival criteria include patients less than 18 years, with diagnosis of acute lymphoblastic leukemia. Exit criteria include those with a history of other immune or other cancers, and the patients with secondary leukemia. Demographic data of patients including age, sex, leukocyte count, flow cytometry and other laboratory findings were collected. Data were analyzed by version 22, SPSS software and parametric tests were used for normal data and nonparametric tests were used for abnormal data. The meaning has described with P-value less than 0.05 .

\section{Results}

The mean age of the patients was $7.56 \pm 3.94$ years and in the range of 1 to 16 years. The evaluating of the patients range shows that 49 patients $(50 \%)$ were 1 to 6 years, $35(35.7 \%)$ were more than 6 to 12 years old, and $14(14.3 \%)$ were more than 12 to $18.51(52 \%)$ were female and $47(48 \%)$ were male. The mean WBC of the studied patients was $4.63 \pm 3.53$ and in the range of 0.1 to 18.60 . The mean RBC of the studied patients was 3.57 \pm 0.68 and in the range of 1.52 to 5.21. The mean PLT of the patients was $130.83 \pm 199.82$ and in the range of 6 to 510 . Immunofenotyp of patients showed that 81 patients $(82.7 \%)$ were Pro B cell, $4(4.1 \%)$ were Pro-B Cell, 5 (5.1\%) were Pro-T Cell and 8 (8.2\%) were T Cell. 87 (88.8\%) patients recovered and 11 patients (11.2\%) also had recurrence. The mean age of PreB cell patients was $7.32 \pm 3.94$ years, Pro-B Cell was $4.50 \pm 2.08$ years, ProT Cell was $12.60 \pm 2.40$ years, and T cell was $8.37 \pm 2.87$ years, which was significantly higher in The Pro-T Cell group than the other groups. $(\mathrm{p}=0.00)$. The mean $\mathrm{WBC}$ of PreB cell patients was $4.59 \pm 3.59$, Pro-B Cell was $2.95 \pm 2.14$, ProT Cell was $4.72 \pm 4.26$ and $\mathrm{T}$ Cells were $5.86 \pm 3.19$, which did not show a significant difference between different immuno-phenotypes $(\mathrm{p}=0.6)$. The mean of RBCs of PreB cell patients was $3.55 \pm$ 0.68 , Pro-B Cell was $3.31 \pm 0.65$, Pro-T Cell was $3.81 \pm 0.96$, and T cell was $3.77 \pm 0.47$, which did not show a significant difference between the different immuno-phenotypes $(\mathrm{p}=0.58)$. The mean PLT of preB cell patients was 193.29 \pm 128.61 , Pro-B Cell was $193.25 \pm 192.07$, Pro-T Cell was $192.07 \pm 188.25$ and T-cell patients were $281.12 \pm 103.28$, which showed a significant difference between the different immuno-phenotypes $(\mathrm{P}=0.33)$. study of the recovery and recurrence status of patients showed that only 11 patients $(13.6 \%)$ had recurrence in Pre B cell patients, but in other immunophenotypes, $100 \%$ of patients had remission, but this difference was not statistically significant $(\mathrm{p}=0.46)$. Age, WBC, RBC, and PLT variables according to the gender of the patients 
showed that there was no statisticaly significant difference in both gender. An examination of both gender immunophenotype showed no statistically significant difference between the phenotypes prevalence in female and male sexes $(p=0.76)$. Recovery and recurrence in both gender showed that the incidence of recurrence in female patients was $9.8 \%$ and in male patients was $12.8 \%$, which was not statistically significant $(0.64)$.

Table 1. Comparison of Age, WBC, RBC and PLT by Immunophenotype

\begin{tabular}{|c|c|c|c|c|}
\hline \multirow{2}{*}{ Variables } & \multirow{2}{*}{ Immunophenotype } & \multicolumn{2}{|c|}{ Indices } & \multirow{2}{*}{ p-value } \\
\hline & & Mean & SD & \\
\hline \multirow{4}{*}{ Age } & Pre B cell & 7.3210 & 3.94280 & \multirow{4}{*}{0.00} \\
\hline & Pro-B Cell & 4.5000 & 2.08167 & \\
\hline & Pro-T Cell & 12.6000 & 2.40832 & \\
\hline & T Cell & 8.3750 & 2.87539 & \\
\hline \multirow{4}{*}{ WBC } & Pre B cell & 4.5917 & 3.59159 & \multirow{4}{*}{0.6} \\
\hline & Pro-B Cell & 2.9550 & 2.14447 & \\
\hline & Pro-T Cell & 4.7200 & 4.26755 & \\
\hline & T Cell & 5.8625 & 3.19282 & \\
\hline \multirow{4}{*}{$\mathbf{R B C}$} & Pre B cell & 3.5554 & 0.68532 & \multirow{4}{*}{0.58} \\
\hline & Pro-B Cell & 3.3125 & 0.65122 & \\
\hline & Pro-T Cell & 3.8100 & 0.96961 & \\
\hline & T Cell & 3.7775 & 0.47261 & \\
\hline \multirow{4}{*}{ PLT } & Pre B cell & 193.2963 & 128.61662 & \multirow{4}{*}{0.33} \\
\hline & Pro-B Cell & 183.2500 & 192.07529 & \\
\hline & Pro-T Cell & 188.8000 & 153.09703 & \\
\hline & T Cell & 281.1250 & 103.28247 & \\
\hline
\end{tabular}

Table 2. Result of remission/relapse by Immunophenotype

\begin{tabular}{lllll}
\hline Immunophenotype & Result & Number & Percent & p-value \\
\hline \multirow{2}{*}{ Pre B cell } & remission & 70 & 86.4 & 13.6 \\
\multirow{3}{*}{ Pro-B Cell } & relapse & 11 & 100 & 0.46 \\
& remission & 4 & 0 & 100 \\
Pro-T Cell & relapse & 0 & 0 & 100 \\
\multirow{2}{*}{ T Cell } & remission & 5 & 0 \\
\hline
\end{tabular}

\section{Discussion}

The results of this study showed that preB cell immunophenotypes were the most prevalent in our study population, and the rate of recurrence was $11.2 \%$. Now, to compare existing data with other studies, we review several articles and compare them with the present data. In one study with a research community close to the current study, Dr. Pedram et al. (2013), in a study entitled "Immuneotype determining by flow cytometry and its relationship with clinical and hematologic index in children younger than 18 years with lymphocytic leukemia" stated that the $72.2 \%$ patients age was under 10 years and $26.8 \%$ of them were older than 10 years. Also, $48.4 \%$ were male, and $31.7 \%$ of patients had leukocyte count of more than 50,000 microliters at the time of admission. Immunophenotypes of early pre B cell was $19.5 \%$, pre B cell was $46.3 \%$, B cell was $7.3 \%$, T cell was $19.5 \%$, and B linage was $4.9 \%$. Overall, $85.4 \%$ of the patients remained in the recovery phase and $14.6 \%$ died (Pedram \& Ghanovat, 2013). In the study of Dr. Pedram et al., the age of the patients and their gender were close to the current study, but the prevalence of different immunophenotypes was different with the present study, because 81 patients $(82.7 \%)$ of our study had Pre B cell, while in the study of the Dr. Pedram et al., although the predominant Pre B cell was the most phenotype, but its prevalence was $46.3 \%$, and finally although the prevalence of recovery was slightly more than the present study, it was reported close to our study. Alavi et al. (2005), developed a study in Tehran, titled "Prevalence of prognostic factors in children with acute lymphoblastic leukemia in Mofid Children's Hospital" and stated that $77.7 \%$ of the patients were between 1 to 10 years and $3.6 \%$ of patients were less than 1 year and $18.7 \%$ were more than 10 years. $58.3 \%$ of the patients were 
male. In $24.5 \%$ of the patients, the leukocyte count was more than $50000 \mu \mathrm{L}$. The pre-B cell immunophenotype was $74.8 \%$, the early pre-B cell was $17.1 \%$, the $\mathrm{T}$ cell was $7.3 \%$ and the $\mathrm{B}$ cell mature was $8.0 \%$. Overall, $79.3 \%$ of the patients remained in the recovery phase and $18.1 \%$ died. $12.9 \%$ of the patients were recurrenced that only $6.2 \%$ of them recovered (Samin, Taghi, Mitra, \& Haleh, 2005). This study not only was consistent with present study in demographic variables such as age and gender, but also the prevalence of the pre-B cell immunophenotype in this study was very close to the current study. The prevalence of recovery was close to this study. Also, Yazdi et al. (2007), in a study titled "prognostic factors in children with acute lymphoblastic leukemia", reported that $1.6 \%$ of patients was less than 1 year, $24.8 \%$ more than 10 years and $73.6 \%$ were among these years. $63.8 \%$ of cases was male. In $28.8 \%$ of patients, white blood cell count was more than $5000 / \mathrm{mL}$. Pre-B cell immunophenotypes were $63.8 \%$, the early pre-B cell were $23.1 \%$, T cells were $12.3 \%$, and mature B cells were $0.8 \%$, which in $88.1 \%$ of cases in category B, CD10 + was marker. In total, $74 \%$ of patients recovered, $16.3 \%$ died and $16.5 \%$ of patients recurrenced (Yazdi et al., 2007). In the study of Olumi et al., the age of the patients was close to the present study, but the Gender dispersal was slightly different, and the majority of the population were boys. As in the present study, the pre-B cell immunophenotype was the most prevalent in that study. The prevalence of recovery was also consistent with our study, although the recurrence of patients in this study was slightly higher than the present study. In fact, the point of view in the present study with other studies is related to pre-B cell prevalence, which has been reported with some differences as the most common immunophenotype in all studies. This finding is also confirmed in other studies. As an example, Azim Rezamand et al. (2014), published an article entitled "Immunophenotype of Acute Lymphoblastic Leukemia in Children," a study of 150 children with acute lymphoblastic leukemia reported that the prevalence of malignancy with the phenotype $\mathrm{T}$-cell was $27.33 \%$, B-cell was $15.33 \%$, Pre-Bcell was $49.33 \%$, and Mixed was $8 \%$. The most prevalent immunophenotypes was pre-B cell and Mixed immunophenotype were reported with the lowest incidence (Rezamand, Rezazadehsaatlou, Sakha, \& Leilabadi, 2014). Also, Borhan Moradveisi and colleagues in Iran (1396) published a study entitled "The Frequency of Clinical and Laboratory Symptoms in Children with Acute Lymphoblastic Leukemia". The prevalence of malignancy with T-cell phenotype was $15.5 \%$, B-cell was $2.4 \%$, Pre-Bcell was 56\% and Early pre Bcell was 26.2\% (Moradveisi, Yazdanifard, \& Fathollahpour, 2017). In addition to the prevalence of the immunophenotype investigating, the second main objective of the present study was to investigate recurrence in patients, which is almost consistent with the current review of studies. However, in some studies, especially in Iran, a higher incidence of recurrence has been reported. for example of Michael E. Kelly et al. In the United States during a study to treat patients with acute pre-B cell leukemia, reported that the recurrence of these patients was 14 of 25 patients (50\%) (Kelly et al., 2013). Of course, in studies outside Iran also reported a recurrence close to the current study, among which Hyery Kim and colleagues in 2014 in the United States, investigating B-Cell acute lymphoblastic leukemia recurrence, reported that among 125 patients with Mature B-Cell acute lymphoblastic leukemia, 19 patients (15\%) had recurrenced (Kim et al., 2014). The present study, with investigating of the immunophenotype prevalence and the incidence of recurrence in Khuzestan province, showed that the frequency of immunophenotypes as well as recurrence incidence in the patients of the present study population is consistent with other Iranian and foreign studies.

\section{Conclusion}

The results of this study showed that pre B cell immunophenotypes with the incidence of $82.7 \%$, had the highest incidence in acute lymphoblastic patients, and the incidence of recurrence was $11.2 \%$. Also, patients with other immunophenotypes did not recur, which this finding may be Because of the insufficent patients to study and compare.

\section{Acknowledgements}

The present research article has been extracted from the "Thesis" conducted as a research project (approved by medical ethic committee: IR.AJUMS.REC.1397.876) funded by Research Deputy of Ahvaz Jundishapur University of Medical Sciences, Ahvaz, Iran.

\section{Conflict of interests}

The authors declare that there is no conflict of interests regarding the publication of this paper.

\section{References}

Aghamohammadi et al. (2008). Chromosomal radiosensitivity in patients withcommon variable immunodeficiency. Immunobiology, 213(5), 447-54. 
Azimi, C., Aghamohammadi, A., Ramyar, A., Safari, Z., Divsalar, K., \& Mahmoodi, M. (2012). Higher frequencies of chromosomal aberrations in lymphocytes of children with acute lymphoblastic leukemia after in vitro gamma irradiation. Tehran University Medical Journal, 70(9).

Barrington-Trimis, J. L., Cockburn, M., Metayer, C., Gauderman, W. J., Wiemels, J., \& McKean-Cowdin, R. (2016). Trends in childhood leukemia incidence over two decades from 1992 to 2013. Int J Cancer, 140(5), 1000-1008.

Belson, M., Kingsley, B., \& Holmes, A. (2007). Risk factorsfor acute leukemia in children: A review. Environ Health Perspect, 115(1), 138-45.

Buffler, P. A., Kwan, M. L., Reynolds, P., \& Urayama, K. Y. (2005). Environmental and genetic risk factors for childhood leukemia: Appraising the evidence. Cancer Invest, 23(1), 60-75.

Chiaretti, S., \& Foà, R. (2009). T-cell acute lymphoblastic leukemia. Haematologica, 94(2), 160-2.

Entezar-e-Ghaem, M., Rahgozar, S., Moafi, A. R., Moshtaghian, J., Esmaeli, A., Abedi, M., \& Montazeri, F. (2013). Evaluation of mRNAexpression profile of ABCG2/BCRP in childhood acute lymphoblastic leukemia. J Shahid Sadoughi Univ Med Sci., 21(5), 575-86.

Espirito, E. A. R., Gaiva, M. A. M., Espinosa, M. M., Barbosa, D. A., \& Belasco, A. G. S. (2011). Taking care of childrenwith cancer: Evaluation of the caregivers' burden and quality of life. Rev. Latino-Am. Enfermagem, 19(3), 515-22.

Hassanzade, J., Mohammadi, R., \& Rajaeefard, A. R. (2013). Risk factors in childhoodlymphoblastic leukemia in Shiraz-Iran (2009): An epidemilogical study. J Gorgan Uni Med Sci., 14(4), 119-124.

Hunger, S. P., \& Mullighan, C. G. (2015). Acute lymphoblastic leukemia in children. New England Journal of Medicine, 373(16), 1541-52.

Karimi, M., Mehrabani, D., Yarmohammadi, H., \& Safari Jahromi, F. S. (2008). The prevalence of signs and symptoms of childhood leukemia and lymphoma in Fars Province, Southern Iran. Cancer Detect Prev, 32(2), 178-83.

Kelly, M. E., Lu, X., Devidas, M., Camitta, B., ..., \& Buchanan, G. (2013). Treatment of relapsed precursor-B acute lymphoblastic leukemia with intensive chemotherapy: POG (Pediatric Oncology Group) study 9411 (SIMAL 9). Journal of Pediatric Hematology/Oncology, 35(7), 509.

Kim, H., Park, E. S., Lee, S. H., Koo, H. H., ..., \& Lee, J. W. (2014). Clinical outcome of relapsed or refractory Burkitt lymphoma and mature B-cell lymphoblastic leukemia in children and adolescents. Cancer Research and Treatment: Official Journal of Korean Cancer Association, 46(4), 358.

Litzelman, K., Catrine, K., Gangnon, R., \& Witt, W. P. (2011). Quality of life among parents of children withcancer or brain tumors: The impact of child characteristics and parental psychosocial factors. Qual LifeRes, 20(8), 1261-9.

Mahoney et al. (2004). The Chernobyl childhood leukemia study: Background \& lessons learned. Environ Health, 3(1), 12.

Masoomeh, H. Y., \& Marjan, H. N. (2011). Comparison of the prevalence of age, sex, and clinical manifestations in children with acute lymphoblastic leukemia and acute myelosytic leukemia. Journal of Islamic Azad University, 13(3), 121-124.

Moradveisi, B., Yazdanifard, P., \& Fathollahpour, A. (2017). Prevalence of clinical and paraclinical features of leukemia among children with acute lymphoblastic leukemia in Sanandaj Besat Hospital, 2008-2013. Sci J Iran Blood Transfus Organ, 14(4), 281-288.

Mousav, S. M., Pourfeizi, A., \& Dastgiri, S. (2010). Childhood cancer in Iran. J Pediatr Hematol Oncol, 32(5), 376-82.

Nikpour, S., Rahimian, S., Shokrabi, S., \& Haghani, H. A. (2010). Relationship between breast-feeding duration and childhood acute leukemia. Iranian Journal of Endocrinology and Metabolism, 11(2), 185-90.

Pedram, M., \& Ghanovat, M. (2013). Determination of Immunity by flow cytometry and its correlation with clinical and hematologic indices in children under the age of 18 years with acute lymphocytic leukemia referring to Shafa-e-Ahvaz Hospital. Ahwaz University of Medical Sciences. Thesis.

Pui, C. H., Yang, J. J., Hunger, S. P., Pieters, R., ..., \& Escherich, G. (2015). Childhood acute lymphoblastic leukemia: Progress through collaboration. Journal of Clinical Oncology, 33(27), 2938. 
Rezamand, A., Rezazadehsaatlou, M., Sakha, K. G., \& Leilabadi, N. D. (2014). Immunophenotypically Subtypes of Acute Lymphoblastic Leukemia Among the patients referred to the Tabriz Children Hospital (2003-2006). Majallah-i pizishki-i Danishgah-i Ulum-i Pizishki va Khadamat-i Bihdashti-i Darmani-i Tabriz, 36(4), 50.

Samin, A., Taghi, C. M., Mitra, M., \& Haleh, A. T. S. (2005). The prevalence of prognostic factors in children with severe lymphoplastic leukemia in Children Children's Hospital from 1997 to 2000. Iranian Journal of Children's Diseases, (3), 237-242.

Vahedi, A., Ëstakhri, R., Goldoost, M., \& Goldoost, P. (2011). Frequency of Acute Myeloid Leukemia Markers Using Flowcytometry in Urmia Imam Khomeini Hospital in One Year. J Mazandaran Univ Med Sci., 21(83), 80-82.

Vazirianzadeh, B., Maraghi, S., Samie, M., Vazirianzadeh, M., Montazeri, M. R., \& Eghbalnejad Mofrad, A. M. (2017). Evaluating some medical lab parameters among hospitalized children in Khuzestan following scorpion sting, SW Iran. IJSS, 5(3), 91-6.

Yazdi et al. (2007). Prognostic factors in children with acute lymphocytic leukemia: A ten-year study in Imam Khomeini Hospital. Medical School of Tehran University of Medical Sciences, 65(12), 61-65.

\section{Copyrights}

Copyright for this article is retained by the author(s), with first publication rights granted to the journal.

This is an open-access article distributed under the terms and conditions of the Creative Commons Attribution license (http://creativecommons.org/licenses/by/4.0/). 